\title{
Personal Rapid Transit: A Sustainable transportation medium for Lucknow
}

\author{
Shumank Deep Srivastava ${ }^{1}$, Ruchin Agrawal*, Dr. A.K Nigam** \\ ${ }^{1}$ Student M.Tech (CTM), AM.A.S.C.E, Assistant Professor*, Associate Professor** \\ Department of Civil Engineering, Bundelkhand Institute of Engineering \& Technology, Jhansi \\ Department of Civil Engineering, Kamla Nehru Institute of Technology, Sultanpur \\ Department of Civil Engineering, Bundelkhand Institute of Engineering \& Technology, Jhansi
}

\begin{abstract}
An ever-increasing growth in the urban areas has put up a new challenge in the domain of urban transportation. The complexity of the problem is enhanced by the limitations in the option available, space available, their inter-relationships and also the ease with which these options serve to cater to the present requirements. Meanwhile as the world is becoming smaller and smaller, the urgency to communicate, travel and transport faster is growing by leaps and bounds. Technology on one hand is acting as a catalyst in this process and on the other hand is providing with solutions to cater to this process. Urban transportation with all its complexities and challenges has attracted the interest of planners and engineers to seek solutions. One such solution is PRT (i.e. Personal Rapid Transit) which has proved promising as a solution to the problem stated above. This paper discusses PRT with respect to technology, its prospect in a developing nation like India and also the feasibility to provide it, if possible, in Lucknow. The paper covers extensively all the aspects of this new means of Urban Transportation and also maps the transportation requirements of Lucknow with a prospective solution with the help of this technology.
\end{abstract}

Keywords: Urban transportation, Personal Rapid Transit, Tramways, Urban Transportation Policy, Ambient Air Quality, Podcar, Guideways

\section{Introduction}

Lucknow is a rapidly growing metropolitan city of Uttar Pradesh. Being the capital the city has to accommodate large volumes of traffic. The city is also known for its historical significance, cultural vibrancy that is rooted in its folk traditions and social harmony. Rapid economical growth is visible in the new developments dawn in the city-scape. The number of people visiting Lucknow has increased many folds. Development has taken off as a result. Social infrastructure such as educational institutes, hospitals and malls has grown with time. At present, Lucknow can be termed as a self sufficient city which has grown remarkably in the recent past, defying all planning norms.

However, the public transport system has not been able to keep pace with this rapid urbanization. The huge and ever-growing vehicular population of Lucknow stands testimony to this fact. Congestion on the roads during peak hours is a common phenomenon, along with alarming pollution levels. Pedestrian safety continues being a major concern.

PRT is envisaged as a solution to the infrastructural constraints and internal mobility problems within Lucknow. It will not only reduce the vehicular congestion on the roads, but will bring down the air and noise pollution levels, increase road safety, saving of time and fuel. Being very flexible and having nominal space requirements, the PRT can pass through congested areas.

The service is more like automated taxis than driverless trains. Contrary to light or heavy rail APMs, PRTs could run feasibility over 3 or 4 passengers. The service potential of PRT is significantly more attractive than most APMs - high enough that it can be expected to significantly affect the car ownership decisions and mode split patterns. Guide ways are arranged in a network topology, with all stations located on sidings, and with frequent merge/diverge points. This approach allows for nonstop, point-to-point travel, bypassing all intermediate stations. The point-to-point service has been compared to a taxi or a horizontal lift (elevator). PRT has the following features that differentiate it from APMs and other forms of traditional transit:

- Non-stop direct service

- Small vehicles: one (1) to six (6) passengers

- Small dedicated guideway

\section{Correct Approach to find a solution for constraints}

The mobility issues of Lucknow are well known. There is need of an organized public transportation system. Also, in the congested areas of Lucknow, encroachments of road space, on-street parking have reduced the effective carriageway of the roads and in turn, reduced the capacity of roads. Along with the phenomenal 
rise in vehicular population experienced in Lucknow, issues of traffic congestion, lack of pedestrian facilities and safety, high levels of air and noise pollution, shortage of parking space, poor condition of internal roads, delays and wastage of man hours are only a few blemishes in the rapid growth of Lucknow.

\subsection{Methodology}

The methodology adopted in designing of a PRT network in Lucknow is presented in brief in given Figure 1.

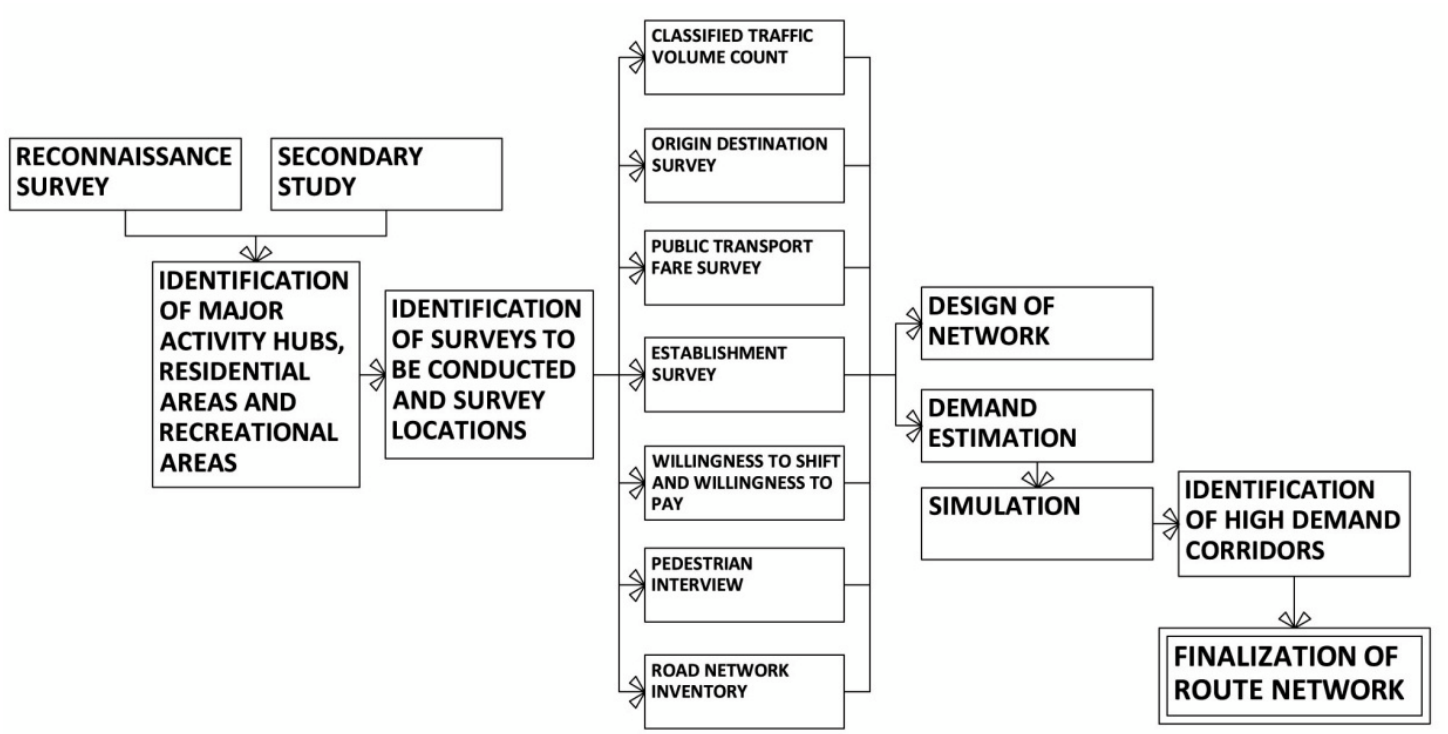

Figure 1: methodology of route network design and demand estimations

\subsubsection{Surveys Undertaken}

Prior to the introduction of a transport system, it is essential to appreciate the mobility patterns of the town. Inputs from interactions with the Government and development authorities have been taken into consideration. Secondary information have been collected and studied in detail. The following surveys were undertaken in this study.

- Secondary Data Collection

- Reconnaissance Survey

- Classified Footfall Count

- Origin Destination Survey

- Public Transport Fare Survey

- Establishment Survey

- Willingness to Shift and Willingness to Pay Surveys

- Pedestrian Interview

- Road Network Inventory

Preliminary traffic surveys were conducted by Delhi Metro Railway Corporation and UPPWD at certain locations in February-March 2012 in order to determine the traffic and travel characteristics of Lucknow, and also to be able to estimate the demand for the first phase of the project. Traffic surveys were taken up in June 2012 across the entire network, inclusive of the previous survey locations. The data collected for the first phase was thus cross checked. These Data has been referred to be a base of the preliminary survey for estimation of traffic demands of the city in order to plan the PRT network

\subsection{Objectives of implementation of PRT in Lucknow}

The study is aimed to ensure safe, affordable, quick, comfortable, reliable and sustainable access for consistently increasing volume of city residents. This is sought to be achieved by:

- Incorporating urban transportation as an important parameter at the urban planning stage rather than being a consequential requirement

- Encouraging integrated land use and transport planning in all cities so that travel distances are minimized and access to livelihoods, education, and other social needs, especially for the marginal segments of the urban population is improved

- Encourage greater use of public transport and non-motorized modes by offering Central financial 
assistance for this purpose

- Enabling the establishment of quality focused multi-modal public transport systems that are well integrated, providing seamless travel across modes

- Establishing effective regulatory and enforcement mechanisms that allow a level playing field for all operators of transport services and enhanced safety for the transport system users

- Establishing institutional mechanisms for enhanced coordination in the planning and management of transport systems

- Introducing Intelligent Transport Systems for traffic management

- Reducing pollution levels through changes in travelling practices, better enforcement, stricter norms, technological improvements, etc.

\subsection{Design of Network}

Designing of a PRT network for Lucknow is a challenging task. The spatial development pattern shows organic growth in city. New Lucknow i.e. Gomtinagar, Indira Nagar etc are comparatively more planned, with residential sectors clearly marked out. Malls and multiplexes have come up, which has had a significant effect on the mobility pattern of the people who reside in and come to Lucknow. The load on the network connecting Lucknow with Kanpur, Barabanki and other parts of the Uttar Pradesh is ever increasing, and so is that on the internal road network.

In the previous sections of this paper, it has been mentioned that the absence of organized public transport has resulted in the growth of car ownership as well as number of intermediate transport modes such as autos, shared autos and cycle rickshaws. Along with high two-wheelers ownership and preference for availing of private modes, the demand of parking spaces have also increased. At present, lack of planning for parking demand has resulted in encroachment of open spaces, footpaths, road spaces by motor vehicles.

\subsubsection{Challenges}

Having understood the spatial pattern and mobility trends of Lucknow, the challenge of designing a PRT network for intra city movement lay in connecting existing and upcoming trip production and attraction centres, yet without disturbing the heritage fabric of old city. It is also crucial to connect with existing and upcoming transport facilities in Lucknow. Thus, Lucknow Railway Station, Kaiserbagh Bus Stand, Alambagh Bus Stand and Chaudhary Charan Singh were also proposed to be integrated with the PRT network.

PRT is a system that can work best in a system of unidirectional closed loops, 2-3 km in length. There are to be no terminal stations. This posed a challenge while designing the network, keeping in mind the efficiency of the network. The route network has to be integrated with the multi level car parks that have been identified by the development authorities so that people would leave their cars at these lots and avail the PRT to reach their destinations.

\subsubsection{Network Configuration}

The major attraction points in Lucknow were identified from the results of the reconnaissance Survey and also the catchment area delineated from the traffic Survey. They were superimposed on a road map, on which the inputs from road network inventory and reconnaissance survey were mapped. A route network of small loops was designed, such that major attraction points lie within $500 \mathrm{~m}$ distance from the nearest station.

The route network has been integrated with multi level car parks that are proposed to be constructed or existing and come under purview of Lucknow Municipal Corporation. The users would avail the PRT to reach their destinations, leaving their personalized vehicles at these lots. Thus, they not only save time, but contribute in reducing pollution and congestion on the narrow internal roads. The route covers Hazratganj where the major activity centres lie and walled city, where the density of development is very high. Major transport nodes, such as Medical College Chowraha (KGMU) and Railway Station have been included. Important activity centers are also integrated.

The total route length is about $14 \mathrm{~km}$ and it will be further extended based on demand. The number of pods that would be operational on this network is estimated as 50 pods per $\mathrm{km}$ increased in a phased manner.

\subsubsection{Scalability}

The unique feature of the PRT is that it is highly flexible. It is possible to build $500 \mathrm{~m}$ in a week. Thus, it is possible to construct a grid of guideways of a certain length of PRT much faster than that of any other dedicated guideway based system such as the LRT, MRT, and Monorail and likewise. Moreover, modifications to an existing network are feasible without much complications or cost implications. The required stretch may be dismantled and realigned as per requirement.

The PRT grid in Lucknow is proposed to be extended into areas where future development is envisaged in the City Development Plan for Lucknow. If needed, new links can be added to this network, based on this 
demand. Areas for future expansion have also been identified.

\subsubsection{Walking Experience in Lucknow}

Like any mega city, walking is not a welcome proposition in Lucknow. Pedestrians walk in extremely unsafe and hostile conditions, in constant conflict with motorized traffic and are easy victims to crashes and accidents. Countless people trip over potholes, slip on sludge, or are grievously hurt by bumping into numerous obstacles strewn along the footpaths. It is also noticeable that there is continuous encroachment of walking space by road side vendors.

It is ironical that despite such high share of walk trips the cities are not walkable. Walkability simply reflects the quality of walking facilities and conditions that make walking safe, comfortable and convenient. In any typical city the pedestrian facilities and network includes sidewalks, path, crosswalk, stairways, curb cuts, ramps and transit stops. These need to be well designed, intricately connected to help pedestrians to take the shortest direct route to destinations and feel safe.

Cities were planned to be walk-friendly. High density, mixed land use, and narrow streets have made walking for work and recreation comfortable, feasible and popular in traditional Indian cities. In any typical city the core could just be $5 \mathrm{~km}$ across and easily walkable within a reasonable time. Studies have shown that more than 40 to 50 per cent of the daily trips in many of our cities have distances less than 5 kilometres. This has enormous potential to convert to non-motorised and especially walking trips. City cores even in mega cities of Kolkata, Mumbai, and many others have retained some of the characteristics of high density, mixed-land use and short trip stretches. But these features are fast disappearing as urban sprawls are expanding.

Car centric infrastructure for seamless, signal free travel through flyovers, expressways and elevated ways, is severing urban landscape, disrupting direct shortest routes of the pedestrians and increasing distances and travel time. Insatiable need for space for motorized vehicles is leading to arbitrary surrender of walking space in cities. Social disdain towards walkers is another cause of neglect of walking space. It is possible for cities to move directly to high end public transport and an urban way of life that is dominated by walking and cycling. Modern infrastructure development is on its peak in cities. If the infrastructure design gives priority to pedestrians, cycling and public transport the mobility paradigm can be transformed and made more sustainable. Walkability improves with enhancement of public transport share. The national walkability index is 0.52 , and that of Lucknow is much lower.

In Lucknow, the poor state of public transport supply has opened up avenues for intermediate modes to monopolize the internal movement, mostly at the cost of comfort and safety of the commuter. During the reconnaissance survey across various locations some pedestrians were interviewed. They were asked about the points from where they had commenced their journey on foot, and where they were destined to. People were found to be walking for distances as large as $2 \mathrm{~km}$. When asked about the distance they would be comfortable walking, the response ranged between 300 and 700 metres.

PRT essentially takes the individuals close to their destination as possible, so that they can walk comfortably from the PRT station. Keeping in mind the extreme weather conditions that are experienced in Lucknow, the comfortable walking distance is estimated at $500 \mathrm{~m}$ only.

\subsubsection{Selection of PRT Routing}

The route network must be integrated with existing car parks that have to be identified. The users would avail pods to reach their destinations, leaving their personalized modes at these lots. Thus, they not only save time, but contribute in reducing pollution and congestion on the narrow internal roads.

The route covers Hazratganj where the major activity centres lie and walled city, where the density of development is very high. Major transport nodes, such as Lucknow Bus Stand and KGMU have been included, important activity centres are also integrated.

\subsubsection{Network Details}

The total route length is $14 \mathrm{~km}$. There are 14 stations along the route connecting major activity areas, work centres and recreational attractions. It provides mobility and connectivity to internal areas of old city. The number of pods on this network is 50 pods per $\mathrm{km}$, increased in a phased manner.

\section{Traffic Scenario in Lucknow}

A travel demand modal and future origin destination based on the projected population and employment were prepared in the detailed survey conducted by the DMRC for preparation of the DPR of Lucknow metro project. In the DPR entire study area has been divided into 127 zones among them 119 are internal zones and remaining are external. 
Automated People Movers: A Futuristic Approach to Modern Transportation Planning

\begin{tabular}{|c|c|c|c|c|}
\hline Description & $\mathbf{2 0 0 1}$ & $\mathbf{2 0 1 1}$ & $\mathbf{2 0 2 1}$ & $\mathbf{2 0 3 1}$ \\
\hline Population & 22.45 lakhs & 29.08 lakhs & 44.41 lakhs & 54.61 lakhs \\
\hline Employment & 6.17 lakhs & 9.19 lakhs & 13.50 lakhs & 17.47 lakhs \\
\hline
\end{tabular}

(Source: Lucknow Master Plan 2021, 2031* WSA Analysis)

There were 1010226 registered vehicles in Lucknow till March 2009 with a growth rate of $7 \%$ in fiscal 20082009. Private transportation providers constitute a very sizeable portion of public transport.

\begin{tabular}{|c|c|c|c|c|c|c|c|c|c|c|c|}
\hline \multirow[b]{2}{*}{ Year } & \multicolumn{3}{|c|}{ Goods Vehicles } & \multicolumn{6}{|c|}{ Passenger Vehicles } & \multirow[b]{2}{*}{ Total } & \multirow[b]{2}{*}{ Growth } \\
\hline & $\begin{array}{c}\text { Heavy } \\
\text { goods } \\
\text { vehicle }\end{array}$ & $\begin{array}{c}\text { Light } \\
\text { goods } \\
\text { vehicle }\end{array}$ & $\begin{array}{l}\text { Wheelers } \\
\text { goods } \\
\text { vehicles }\end{array}$ & Buses & Taxi & $\begin{array}{c}\text { Auto } \\
\text { rickshaw }\end{array}$ & $\begin{array}{c}\text { Two } \\
\text { wheelers }\end{array}$ & $\begin{array}{c}\text { Four } \\
\text { wheelers }\end{array}$ & $\begin{array}{c}\text { Tempo } \\
\text { taxi }\end{array}$ & & \\
\hline 2004-05 & 5303 & 4780 & 2392 & 3553 & 4602 & 1544 & 601745 & 97317 & 7381 & 728617 & \\
\hline $2005-06$ & 5541 & 5018 & 2782 & 3831 & 5080 & 2228 & 660332 & 106874 & 7475 & 799161 & $10 \%$ \\
\hline 2006-07 & 5893 & 5783 & 3197 & 3914 & 6283 & 4762 & 720158 & 105447 & 8233 & 863670 & $8 \%$ \\
\hline $2007-08$ & 6066 & 6783 & 3576 & 3842 & 7083 & 5008 & 771846 & 129316 & 8216 & 941691 & $9 \%$ \\
\hline 2008-09 & 6242 & 7657 & 3776 & 3741 & 7399 & 5015 & 825088 & 142861 & 8447 & 1010226 & $7 \%$ \\
\hline
\end{tabular}

Table 2: vehicle registration Data (2004-2008) Source Regional Transport Office Lucknow

Considering the above surging volume of traffic in the city an alternative transportation solution is required in order to fulfil the needs of Lucknow. Besides this in old Lucknow area there a frequent traffic jam caused due to heavy traffic and low availability of a mass transit system.

\subsection{Trip information}

The trip information obtained from the survey has been analyzed with respect to distribution of total trips by mode. The daily trips by various mediums are presented in table $\mathbf{3}$ and fig. $\mathbf{2}$.

Table 3 distribution of motorized trips

\begin{tabular}{|c|c|c|c|}
\hline Mode & Internal trips & External trips & Total trips \\
\hline Two-wheeler & 1342500 & 43913 & 1386413 \\
\hline Car & 156225 & 60200 & 216425 \\
\hline Auto rickshaw & 71525 & 15938 & 87463 \\
\hline Public transit & 316850 & 157000 & 473850 \\
\hline Total & $\mathbf{1 8 8 7 1 0 0}$ & $\mathbf{2 2 1 6 4 0}$ & $\mathbf{2 1 6 4 1 5 1}$ \\
\hline
\end{tabular}
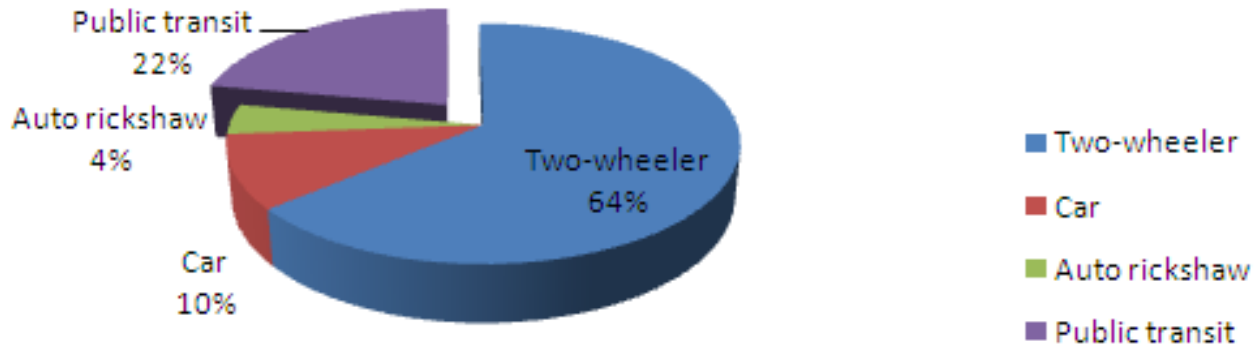

Fig 2.1: Mode Split-Motorised

\section{Population Density of Lucknow}

As described in the Census of India 2011, Lucknow had population of 6,000,455. There was change of $35.79 \%$ in the population compared to that as per 2001 census. In the previous census of India 2001, Lucknow District recorded increase of 32.03 percent to its population as compared to 1991 census. Between 1991 and 2001 the population registered a growth of 32.03 percent which was much less than the 37.14 percent which was registered between 1981 and 1991 decade. The initial provisional data suggest a density of 1,815 in 2011 compared to 1,443 of 2001.Total area under Lucknow district is of about 2,528 square kilometres (976 sq mi). However, the density of population was much above that obtained at the state level (690 persons per $\mathrm{km}^{2}$.). A very high percentage of the total population (36.37 percent) resides in rural areas which means that barely 
around 63.3 percent is urban in nature. Thus on the basis of these figures Lucknow can be divide in two parts namely

- Lucknow rural area

- Lucknow Urban Agglomeration

\subsection{Urban Region Overview}

As per data released by Govt. of India for Census 2011, Lucknow is an Urban Agglomeration coming under category of Million plus Urban Agglomeration or City. Lucknow city is governed by Municipal Corporation and is situated in Lucknow Urban Region. The total population of Lucknow Urban Agglomeration or Metropolitan region is 2,901,474. Yet Lucknow city has population of 2,815,601, this comprises of old city area and those that fall under the governance of Lucknow Municipal Corporation.

\section{Ambient Air Quality of Lucknow}

With reference to "Assessment of ambient air quality of lucknow city during pre-monsoon, 2011" conducted by Indian institute of toxicological research, Lucknow the observations given in table 1, were presented. The survey was done along the major traffic routes of the city and the following observation were made from the data collected:

- The Respirable Suspended Particulate Matter (RSPM) (PM10) level at all monitoring locations of residential, commercial and industrial areas were higher than the NAAQS.

- Fine Particle (PM2.5) level at all the monitoring locations of residential, commercial and industrial areas were higher than the NAAQS $(60 \mu \mathrm{g} / \mathrm{m} 3)$

- The concentration of gaseous pollutants, $\mathrm{SO} 2$ and NOx were well below the prescribed NAAQS (80 $\mu \mathrm{g} / \mathrm{m} 3)$ at all the locations.

- Decreasing trend for the RSPM was found at all the locations over the 2006 data till 2010 except at Vikas Nagar, Hussainganj, Charbagh and Aminabad. The findings of 2011 survey showed higher level in most of locations, which can be a result of construction activities is progress in that locations.

And after considering the above findings it made the following recommendations:

- Public mass transport must be strengthened to minimize use of personal vehicle.

- Improvement in the traffic management.

- Encroachment should be removed for smooth flow of traffic.

- Public awareness programme for automobile pollution.

- Pressure horns to be removed from all vehicles and avoid use of horn.

- Government should increase the parking charges on hourly basis to discourage the use of personal vehicle.

- $\quad$ Congestions charges for certain area for peak hours.

\subsection{Environmental impacts}

\section{Sustainability aspects of Personal Rapid Transit}

The PRT project does not include any major construction work, widening of roads or other activities which contribute towards negative environmental impacts such as air pollution, water pollution, noise pollution, community severance and impacts on vegetation/land degradation by the implementation of proposed PRT project.

PRT offers noise levels which are likely to be undistinguishable from the background noise, and will cause no vibration problems in the buildings it passes. The guideway has to be segregated, and there are potential problems of community severance here, but in practice much of the tracks are elevated so that footpaths can pass underneath, and it will pass over all roads it crosses. The design intention is to cause no added severance. There are unavoidable problems of visual intrusion, but these can be minimized by the small scale of the infrastructure and careful design, and will be far less severe than with other forms of tracked public transport. In some aspects the system can add positively to the cityscape, creating an exciting and dynamic addition, especially where it can be integrated directly into new development.

PRT is a solution that is environment friendly, cost effective and a comfortable mode of transport to attract people to choose that mode. It can also be integrated with solar panels in the pods. It is pollution free and sound less vehicle. PRT has $72 \%$ carbon emissions benefit over car transport and $54 \%$ over train/ bus.

\subsection{Social impacts}

PRT is developed with consideration of the wish of people to travel with desired companions when possible. During peak hour some voluntary ride sharing is anticipated but for much of the day a truly personal travel experience will be provided. This is a vital contribution to wider social objectives in the present era. PRT will offer a premium transport system for the whole of the City and also a new experience of shared travelling. 
Shared mode of travel in a way has many advantages over the personal mode; one can travel without spending a sizeable amount.PRT is a system that provides comfort convenience, and faster mode of travel; to overcome from the personal mode of travel. Public transport system has all the advantages over the personal transport,

- It requires zero investment from ones pocket,

- Low travelling cost,

- Reduces traffic on roads,

- Decreases travel time

- Lesser emissions

- Energy savings

While PRT though is a public mode of travel but is sophisticated enough that people would feel pride travelling in that. It has all the comforts of a luxurious car with intelligent system, AC, etc. best part is while travelling in this vehicle one can have peace of mind and sit comfortably and reach thy destination, which is otherwise not possible complete concentration is in managing traffic and getting out of it, a person is always stressed while travelling and at work. The benefits include:

- Reduction in travel time - Savings in travel time and money accruing to the PRT users compared with their previous journeys, estimated as the change in the weighted costs of the time components of travel when PRT is introduced, plus the saving in car operating cost of those car users who transfer. With well established communication lines between the vehicle, command control centre and the PRT stations, the control room will be able to redirect the vehicles and help to reach the destination in pre-determined time. When Traffic Management System gets implemented across the city, these vehicles would get to have information on the traffic density and probable courses of action to reach the destination in time.

It can also be integrated with other modes of transport. It becomes really uncomfortable when a person gets down from one mode of transport and is searching for another and then moving ahead in the same traffic. Whereas PRT can be well integrated with one mode or the other. One doesn't has to get down and then start searching for another mode, it will be waiting for you to hire it.

It's simple design helps it even to penetrate into the buildings and can easily connect buildings. PRT being a light weight vehicle and simple in design provides a very comfortable and different experience of running within buildings. It can be easily set up in a mall or multiples and one needs not wall throughout with all the shopping bags in hand, can easily board a PRT and move in that. This gives such a relaxing shopping situation that it becomes easier to shop without being exhausting running through one corner or mall to the other as well up and down.

Accidents and fatalities are undesirable occurrence of the transportation system. Intelligent Transportation System helps to minimize the risk of accident occurrence. Monitoring vehicle speed and its location will reduce the number of crashes and the probability of controlling number of fatality.

- Emergency medical evacuation service: Podcars can also be employed as a MEDIVAC. Average response time for the vehicle is very less as it is waiting at stations for the passengers. Many people die during road accidents because of untimely medical aid since the ambulances are not able to reach the accident site due to heavy traffic most of the times collapses in the ambulance or at hospital gate. PRT MEDIVAC is conveniently available and moves overhead without any traffic jams and people get medical aid at a much faster rate. MEDIVAC is fully equipped with all the necessary life saving devices for an ambulance. It can directly penetrate into the nearest hospital building, and patients can be provided medical aid much faster.

With various systems installed in the vehicle, PRT command and Control Centres, Integration and coordination becomes a key factor for providing different experience to the citizens of and automatically brings in a satisfaction factor.

With intelligent display units inside the vehicle and at stations providing information on stops, citizens enhance their productive time without having to waste their time at bus stops / stands not knowing when the next bus would be arriving. 
Automated People Movers: A Futuristic Approach to Modern Transportation Planning

\begin{tabular}{|c|c|c|c|c|c|c|c|c|c|c|c|c|c|c|c|c|c|c|}
\hline \multirow[t]{2}{*}{ Location } & \multicolumn{3}{|c|}{ RSPM } & \multicolumn{3}{|c|}{ PM2.5 } & \multicolumn{3}{|c|}{$\mathrm{SO} 2$} & \multicolumn{3}{|c|}{ Nox } & \multicolumn{3}{|c|}{$\mathrm{CO}$} & \multicolumn{3}{|c|}{03} \\
\hline & Min & Max & Avg & Min & Max & Avg & Min & Max & Avg & Min & Max & Avg & Min & Max & Avg & Min & Max & Avg \\
\hline \multicolumn{19}{|c|}{ Residential Area } \\
\hline Aliganj & 107.3 & 158.1 & 136.8 & 53.4 & 71.3 & 63.0 & 10.7 & 14.5 & 12.2 & 20.5 & 32.1 & 26.1 & 198.0 & 803.8 & 477.6 & 55.2 & 135.9 & 83.7 \\
\hline Vikas Nagar & 140.2 & 168.7 & 158.9 & 62.4 & 77.3 & 69.5 & 11.4 & 13.2 & 12.5 & 23.6 & 30.1 & 27.0 & 128.2 & 733.9 & 349.5 & 62.2 & 125.6 & 97.8 \\
\hline Indira Nagar & 140.5 & 342.5 & 244.8 & 68.5 & 85.3 & 78.9 & 15.4 & 22.4 & 19.2 & 27.4 & 34.2 & 30.1 & 454.4 & 1339.7 & 978.6 & 50.3 & 145.0 & 88.8 \\
\hline Gomti Nagar & 136.7 & 276.0 & 186.4 & 58.8 & 79.3 & 67.1 & 11.9 & 22.4 & 15.8 & 22.9 & 27.5 & 24.9 & 326.2 & 932.0 & 466.0 & 45.6 & 135.6 & 79.5 \\
\hline \multicolumn{19}{|c|}{ Commercial Area } \\
\hline Hussaingan $j$ & 169.3 & 224.2 & 187.6 & 66.2 & 78.4 & 73.1 & 15.3 & 19.2 & 17.2 & 33.1 & 38.9 & 37.4 & 466.0 & 1328.1 & 1130.0 & 51.3 & 175.9 & 105.8 \\
\hline Charbagh & 177.1 & 288.9 & 214.1 & 82.9 & 108.9 & 95.0 & 11.7 & 18.5 & 14.5 & 30.1 & 39.7 & 34.8 & 349.5 & 1770.8 & 1001.9 & 55.3 & 168.9 & 126.3 \\
\hline Alambagh & 189.7 & 291.4 & 250.4 & 78.4 & 89.3 & 83.4 & 13.7 & 20.4 & 18.6 & 30.4 & 38.3 & 35.1 & 337.8 & 1374.7 & 1071.8 & 65.8 & 159.6 & 122.3 \\
\hline Aminabad & 138.2 & 224.4 & 183.9 & 66.8 & 83.1 & 75.8 & 12.6 & 20.6 & 17.4 & 27.2 & 32.0 & 29.6 & 244.6 & 1316.5 & 862.1 & 75.3 & 115.5 & 95.6 \\
\hline Chowk & 149.8 & 303.7 & 252.9 & 78.6 & 90.4 & 81.3 & 14.0 & 19.9 & 16.8 & 31.2 & 41.6 & 36.9 & 267.0 & 1339.7 & 1025.2 & 62.9 & 172.1 & 131.4 \\
\hline \multicolumn{19}{|c|}{ Industrial Area } \\
\hline Amausi & 129.3 & 217.4 & 163.0 & 64.7 & 71.5 & 67.6 & 11.9 & 17.5 & 14.3 & 26.5 & 31.0 & 29.0 & 233.0 & 1165.0 & 803.8 & 35.2 & 102.1 & 66.7 \\
\hline NAAQS & \multicolumn{3}{|c|}{100} & \multicolumn{3}{|c|}{60} & \multicolumn{3}{|c|}{80} & \multicolumn{3}{|c|}{80} & \multicolumn{3}{|c|}{4000} & \multicolumn{3}{|c|}{180} \\
\hline $\begin{array}{c}\text { WHO } \\
\text { Guidelines }\end{array}$ & \multicolumn{3}{|c|}{50} & \multicolumn{3}{|c|}{25} & \multicolumn{3}{|c|}{20} & \multicolumn{3}{|c|}{$40^{*}$} & \multicolumn{3}{|c|}{$\ldots$} & \multicolumn{3}{|c|}{$10^{* * *}$} \\
\hline
\end{tabular}

RSPM, SO2, $\mathrm{NO}_{\mathrm{x}}(\mathrm{N}=6), \mathrm{PM}_{2.5}(\mathrm{~N}=4), \mathrm{CO}$ and $\mathrm{O} 3=$ One hour Average, $*=$ Annual Average, $* *=8$ Hours Average, NAAQS=National Ambient Air Quality Standards

Table 4: findings of Indian institute of toxicological research, Lucknow for its survey of ambient air quality( source: IITR

This system will also affect the lower income groups of the society. Like rickshaw runner will have good impact on their income. With the coming up of this system it will reduce traffic on the roads and the rickshaws will be able to make more number of

trips on the same roads and can have higher income.

Presently running IPT are very unsafe modes of transport with people hanging out of them. These vehicles are so prone to accidents that they can cause risk not only for themselves but also for people coming their way. While PRT is very safe mode of travel that one can sit tensionless in the vehicle and get down at the desired stop.

\subsection{Economic Benefits}

The cost of elevated construction is lower than an equivalent footbridge. The smaller-scale structure facilitates running the guideway as mostly single track in interconnected loops. The network is able to penetrate built-up areas more closely than the larger-scale public transport. Stations are low-cost whether at grade or elevated, and can be relatively closely spaced to reduce walking distances to the service without affecting journey speed or capacity of the other parts of the system.

PRT is an economical mode of transport with a commuting cost in between the fare of bus and expenditure on car. Both the installation and running cost of PRT is less which makes it economical.

\section{Conclusion}

From the above study it is significantly remarkable that there is a requirement of an alternative transportation medium that can meet the increasing population trends. The technical specifications of Personal Rapid Transit Systems make it clearly visible that these systems can prove to be an efficient transportation model for Lucknow city that too without affecting the environment. These systems can be an effective and strong public mass transit that can function not only as a major means of transportation in dense areas as well as it can be employed as a feeder network for the proposed metro service for the city of Lucknow.

\section{References}

[1]. Detailed Project report of Lucknow Metro Railway project

[2]. “Assessment of ambient air quality of lucknow city during pre-monsoon, 2011", findings of a random survey, Presented on world environment day, 2011, by Indian institute of toxicological research, Lucknow

[3]. Census 2011, population of Lucknow Urban agglomeration, Government of India

[4]. A Report on Urban Transportation Policies, Ministry of Urban Transportation, Govt of India

[5]. Amritsar Personal Rapid Transit System Detailed Project report by M/s Fairwood Green Transport

[6]. Chapter 18, handbook of transportation engineering, by Myer Kutz, volume 2 